

2.0 Autorizase al Intendente de Talca, para que nombre dando cuenta, uña persona idónea que desempeñe esta escuela, con el sueldo de doscientos cuarenta pesos anuales.

$3,^{\circ}$ Impútese este sueldo a la partida 56 del presupuesto del Ministerio de Instruccion Pública.

Tómese razon i comuniquese.

Hontr.

\section{Waldo Silva.}

\section{Santiago, agosto 4 de $18 \%$ \%.}

Con lo espuesto por el intentente de Concepcion en la nota precedente, lecreto:

Los alumnos interno del Liceo de Concepcion pagaràn desde el año prúximo venidero una pension deciento diez pesos anuales cada uno, en lugar de ciento con que contribuian segun el artículo $22^{*}$ del decreto de 30 de marzo de 4833.

Tómese razon i comuniquese.

Montt.

\section{Waldo Silva.}

\section{Santiago, agosto 3 de 1837.}

Vista la terna formada por la Facultad de Matemáticas de la Universidad, i que me ha presentado el Rector de dicha corporacion, en uso de la facultad que me confiere el artículo $4{ }^{\circ}$ de la lei de 19 de noviembre de 1842 , vengo cil nombrar Decano de la espresada Facultad de Matemáticas, a don Francisco de Borja Solar que me ha sido propuesto en primer lugar.

Tómese razon i comuniquese.

MONTY

\section{Waldo Silva.}

\section{Santiago, agosto bै de 1857.}

Vista la terna formada por la Facultad de Humanidades de la Universidad, i que me ha presentado el Rector de dicha corporacion, en uso de la facultad que me confiere el articulo $4 .^{\circ}$ de la lei de 19 de noviembre de 1842 , vengo en nombrar Decano de la espresada Facultad de Ifumanidades, a don Salvador Sanfuentes que me ha sido propuesto en primer lugar.

Tómese razon i comuniquese.

Montr. 
Admilese lá renuncia que hace de su destino el profesor de Derecho Canónico en la sesion Universitaria del Iustituto Nacional, don Mfigtel M. Güemes i se nombra. a don Rafael Fernandez para que en calidad de profesor interino desempeñe la espresada clase. Abónese al nombrado el sueldo correspondiente.

Tómese razon i comuníquese.

MoNTt.

\section{Walio Silva.}

\section{Santiago, agostö 10 de 1837.}

Con lo espuesto en la nota precedente,

decreto:

4. Establécese en el paeblo de Lota, una escuela primaria para mujeres que funcionará, en el local costruido al efecto por don José María Acuña, i en la cual se enseñarím gratzitamente los ramos siguientes: lectura, escritura, aritmética, catonismo de dectrina cristiana, gramática castellana, costura i bordado.

2.0 Autorizase al Intendente de Concepeion para que nombre dando cuenta, una persona idónca que rejento el establecimiento, con la dotacion de doscientos cuerenta pesos anuales.

3.0 Impútese el sueldo decretado at la partida 36 del presupuesto del Ministerio de Instraccion Pública.

Tómese razon i comuníquese.

MoNTt.

Waldo Silva:

Santiago, agosto 44 de 1857 .

Vista lä terna formada por la Facultad de Leyes de Ia Univerisdad, i que me ha: sido presentada por el Rector de dicha corporacion, en uso de la atribucion que me confiere el articulo $4.0^{\circ}$ de la lei de 19 noviembrede $18 / 2$, vengo en nombrar Decano de la espresada Fácultad de Leyes a don Juan Francisco Heneses, que me ha sido prepuesto en primer lugar.

Tómese razon i comuníques.

Montt.

Waldo Silva. 


\section{Suntiago, agosto 14 de 1807 T.}

Fista la terna fornada por la Facultad de Teolujia de la Eniversilad, i que me. ha presentado ol Rector de dicha corporacion, en uso de la atribucion gue me confiere el artículo '́.0 de la lei de 19 de noviembre de 1842 , vengo en nombrar Decano de la Facultad de Teolojia al presbitero don José Xanuel Orrego, que me ha sito propuesto en primer lugar.

Tómese razon i comuniqueso.

NOATr.

Faldo Silia.

\section{Santiago, agosio 2 de 18:3ĩ.}

En vista de la nota precuiente i documentos adjuntos uecreto:

1.0 Créase una escuela nocturnà para artesanos en el puerto tid Tomé que funcionará en el local provisto de los úliles necesarios que proporcione la Hunicipalidad respectiva, $i$ en la etal se enseñarán gratuitamente los rumos siguientes: lectura, escritura, aritmética, catecimmo de doctima cristiana, sramática castellana i dibujo lineal,

2.0 Nómbrase para dirijir esta escuela al preceptor de la fiscal de hombres establccida en ticho puerto, don Nolyerto Solis Obando con un sobre suiduo de cien jesos anuales.

3. Impútese el espresado sobre-sueldo a la partila 36 del presapuesto del 31 irio de Instruccion Pública.

Tómese razon i comuniquuese.

HoNTt.

Waldo Silva.

Santiago, agosto 9 s de $185 \%$.

Con lo espuesto en la nota que precede,

He venido en acordas i decreto:

4. Estabiécese anexo al Liceo de Talca una escuala nocturna para adultos, en ta cual se enseñarin gratuitamente los ramos sigujentss: lectura, escritura, aritmética dibujo lineal i esplicaciones orales te relijion.

2. Nómbrase diuctar úe dicha cscuela al precenor de la escuela diuma anexa. ai misno Liceo don Bnenarentura Gonzalez, (quien descmpeñará la clase de bibtjo lincal a que estit obigato por decreto de 19 de mayo tiltino.

3. Nómbrase preceptor de los ramos de lectura, estritura i aritmética en el 
eitado establecimiento al preceptor Hunicipal don José Tomas Letelier a quien se abonará desde que principie a prestar sus servicios el suello de cien pesos anuales, que se imputará al item 22 de la partida 47 del. presupuesto del Ministerio de Instruccion Pública.

4.0 La escuela do adultos referida funcionará curante dos horas por la noche los dias lúses, mártes, Miércoles i Viérnes.

Tómese razon i comuniquese.

Montr.

Faldo Silva.

Santiafjo. agosto 20 de $18: 37$.

Coni lo espuesto on la nota precelente i considerando que el ví́tico asignado a: Ios Visitadores die Escuelas, no es suficiente para que sus empleados puedan satisfacer sus gastos de trasporte que tienen que hacer en los frecuentes viajes que deben ejectuar en cumplimiento de las obligacion que les imponen sus destinos.

Decreto:

1:0 Los visitadores de cscuela de la Fepública gazarín en lo sticesivo a mas del suelto que les esta asignado, un peso de gratificacion por cada dia que pasaren fuera de la Ciapital de la provincia de sus dectinus.

2. La gratificacion señatala al visitador de escuelas de ha provincia de diacama por clecreto de 5 de Noviembre de $18: 0,6$ i 10 de junio último, se arreglará en adelante a lo dispuesto en el articulo precelente.

3.0 Inpútese esta gratifacacion a la partida 60 del presupuasto del Ministerio de Instruccion públiça i consultese oportmamente en el lugar correspondiente del referido aresupiesto.

Tómese razon i eomuniquese.

MonTt.

Waldo Silia.

Santiago, agosto 27 de $18: \hat{8} 8$.

Con lo espuesto en la nota que precede, estiéntase el correspondiente díploma a miembro corresponsal de la facuitad de Filosofía i Humanidades en la ciudad:

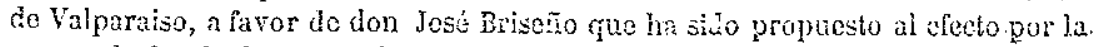
espresada facultad con aprobacion rial Consejo Eniversiario,

Cominiquese.

Hontr.

Waldo Silva. 


\section{Santiago, agosto 28 de $183 \%$.}

Con lo espuesto en la nota que precede admitese la renuncia que hacen don. Mariano Fuentes i don José Maria Rojas del cargo de inspectores en la Escuela Normal, i se nombra para que desempeñen dichos empleos a don Pedro José Diaz i.don Ramon Martinez, a quienes se abonará el sueldo correspondiente desde quo. principien a prestar sus servicios.

Tómese razon i comuaíquese.

Moxtт.

Waldo Silva.

\section{Santiago, setiemóre 21 de $183 \%$.}

Con lo espuesto por el Intentente del Mauble en sus notas fecha 21 de Jalio: último, núm, 111 i fecha 12 del actual, núm. 14ś.

He venido en acordar i decreto:

1. Establéccse en Ninhue, departamento de Itata, una escuela de mujeres, en: la cual se enseñarán los ramos siguientes. letura, escritura, catecismo, aritmética, costura i bordado.

2. Acéptase la oferta que hace el vecindario de dicho punto de un local provisto de los muebles precisos para que funcione la referida escuela.

3.0 Nómbrase jreceptora del mencionado establecimiento a doña Petronila Salvo, a quien se abonará el sueldo de trescientos pesos anuales desdo que prina prestar sus servicios.

4.0 Impútesc por alsora cl suello decrotado a la partida 56 del presupuesto del. Ministerio de Instriaceion Pública i consúltese oportunamente en el lugar. correspondiente del referido presupuesto.

5. ${ }^{\circ}$ El Intendente del Xauble comunicará al Ministerio de Intruccion Pública el. dia en que el nuevo establecimiento comience a funcionar i el número de alum-. nos con que se hubiere abierio.

Tómese razon i comuníquese.

\section{HONTT}

\section{Waldo Silva,}

\section{Sontiago, seticmbre 22 de 1837 .}

Gon lo espuesto en la nota que precede.

Decrito:

4. Establécese on la escuela modelo de Chillan una escuela nocturna para adultos, en la cual se enseñarán gratuitamente lus ramos siguientes: lectura, eseritura, arimética, ortografia castellana i esplicaciones orales de relijion, 


\section{$-267-$}

2. Nónibrase preceptor de esta escuela nocturna al preceptor de la referida escuela modelo, aquien se le abonará un sobre-sueldo de cien pesos antales, siempre que acredite mensualmente a la respectiva oficina pagadora, una asistencia media de currenta alumnos

3.0 Impútese por ahora el sueldo decretado a la partida 36 del presupuesto del Ministerio de Instruccion pública i consúltese opartunamente en el lugar correspondiente de dicho presupuesto.

Tómese razon i comuníquese.

\section{MoNTt.}

Maldo Silva. 